\title{
Use of 3D Laser Scanning and Additive Technologies for Reconstruction of Damaged and Destroyed Cultural Heritage Objects
}

\author{
Vadim Parfenov ${ }^{1, *(\mathbb{D}}$, Sergei Igoshin ${ }^{2} \mathbb{D}$, Dmitriy Masaylo $^{2}$, Alexey Orlov ${ }^{2}$ and Dzmitry Kuliashou $^{3}$ \\ 1 Department of Photonic, Faculty of Electronics, St. Petersburg Electrotechnical University, \\ 197376 St. Petersburg, Russia \\ 2 Institute of Mechanical Engineering, Materials and Transport, Peter the Great St. Petersburg Polytechnic \\ University, 195251 St. Petersburg, Russia; sergei.igosshin@gmail.com (S.I.); dmasaylo@gmail.com (D.M.); \\ orlov_alexey88@mail.ru (A.O.) \\ 3 Center of Prototyping, 197376 St. Petersburg, Russia; sdimasik1102@gmail.com \\ * Correspondence: vaparfenov@etu.ru
}

check for

updates

Citation: Parfenov, V.; Igoshin, S.;

Masaylo, D.; Orlov, A.; Kuliashou, D. Use of 3D Laser Scanning and Additive Technologies for Reconstruction of Damaged and Destroyed Cultural Heritage Objects. Quantum Beam Sci. 2022, 6, 11.

https://doi.org/10.3390/

qubs6010011

Academic Editors: Swee Leong Sing and Wai Yee Yeong

Received: 28 December 2021

Accepted: 22 February 2022

Published: 3 March 2022

Publisher's Note: MDPI stays neutral with regard to jurisdictional claims in published maps and institutional affiliations.

Copyright: (C) 2022 by the authors. Licensee MDPI, Basel, Switzerland. This article is an open access article distributed under the terms and conditions of the Creative Commons Attribution (CC BY) license (https:// creativecommons.org/licenses/by/ $4.0 /)$.

\begin{abstract}
Three-dimensional laser scanning is a novel measurement technique that is frequently used for the documentation of cultural heritage $(\mathrm{CH})$ objects. In the process of 3D scanning, one can obtain computing 3D models of artworks to be documented. It allows one to produce detailed digitized archives of important $\mathrm{CH}$ objects. Moreover, the use of 3D scanning enables the digital reconstruction of architectural fragments, sculptures, and other artworks. One more important application of this technique relates to the creation of molds and replicas for replacements of outdoor $\mathrm{CH}$ objects in case their preservation requirements do not allow them to remain in their original place due to the influence of environmental factors. One of the most effective ways of creating replicas is the use of laser additive technologies. Therefore, the combination of 3D scanning and additive technologies is a very promising way of preservation of $\mathrm{CH}$. This paper describes several case studies concerned with the combined usage of 3D laser scanning and additive technologies for digital reconstruction and replication and of outdoor sculptures in St. Petersburg city. One of them is the reconstruction of the zinc sculpture "Eva at the fountain" (XIX century, England), which was destroyed during WWII. Its replica was created by means of laser stereolithography. Eventually, one more project is related to the reconstruction of the fragment of the sufficiently damaged cast-iron XIX century monument. This object was reconstructed using two laser technologies: direct metal laser sintering (DMLS), and laser cladding (LC).
\end{abstract}

Keywords: laser additive technologies; 3D printing; 3D scanning; cultural heritage object; restoration; reconstruction; end-to-end technologies

\section{Introduction}

In recent decades, one of the most serious challenges in the preservation of cultural and historical heritage has been the rapid decay of exterior monuments due to environmental deterioration, especially in large industrial megapolises. However, in addition to poor environmental conditions, sculptures and other cultural heritage objects also suffer from natural disasters and vandal attacks, which also result in damage and sometimes total loss.

In this context, the question on the need to reconstruct damaged $\mathrm{CH}$ objects or to gradually replace them with copies with subsequent transfer of originals to closed museum premises was on the agenda. According to the world practice, today, it is the only opportunity to preserve the most important monuments of the past for descendants, at least their most valuable ones. Although the idea of replacing originals with copies has always caused and still causes an ambiguous attitude in society and even among the museum community, unfortunately, there is no other way to save $\mathrm{CH}$ objects from destruction 
nowadays. It should be noted that the idea of the replication of monuments is not new. Michelangelo's masterpiece, the famous marble sculpture of David, which has remained for almost 370 years in Piazza della Signoria in Florence, was copied in 1873 when the original David was moved for eternal storage in the Gallery of Academy of Fine Arts in the city.

However, nowadays, when museum curators, art experts, and restorers gradually come to an agreement on the need for copying monuments in principle, the question arises of what technologies may be used (and most importantly, are acceptable) when creating copies. Over the years, copies of sculptural monuments were created from different materials. In the 1980s, natural marble was used, and copies were made by "manual" cutting of sculptures and bas-reliefs of stone blocks. Later, cement with marble powder was used, but now various types of synthetic materials are used instead of cement. Such a composition is called "artificial stone". However, this approach, which has been widely adopted in recent years, has many serious shortcomings. The most important of them is that copies made of artificial stone are obtained as a result of forming the original sculpture, and this inevitably leads to a significant physical and chemical impact on its surface. Molding can lead to mechanical damages in the form of fractures and broken small parts of monuments occurring during the mold removal. In addition, the impact of chemical reactions of molding materials with the monument substrate can also be significant.

Now, there is a very attractive alternative to the above-mentioned approach. Innovative $3 \mathrm{D}$ laser scanning technology in combination with stone milling machines with numerical software control $(\mathrm{CNC})$ is attractive way of replicating cultural heritage objects. This allows copying sculptural monuments made of natural stone (marble, limestone, granite, etc.). The main advantage of this method is that it is contactless and does not have any negative impact on the original monument. Thanks to this, laser-based contactless copying technology is now widespread in some European countries [1-3].

Ultimately, copying $\mathrm{CH}$ objects using natural stone is expensive, and it is not always advisable to use this approach. A different approach can be used to replicate ordinary artifacts and to create copies of lost fragments of works of art for modeling restoration work. Such tasks can be resolved by means of using laser additive technologies. In recent years, several research groups reported case studies where different 3D printing techniques were used, but all known works are not systematic [4-6]. The purpose of this work is to demonstrate the principal possibility of the application and benefits of the use of end-to-end $3 \mathrm{D}$ scanning technologies and the reproduction of scan results using $\mathrm{CNC}$ and $3 \mathrm{D}$ printers with a laser source for repairing and reconstructing cultural heritage objects. In this paper, we describe the results of cases studies on the reconstruction of $\mathrm{CH}$ objects in the city of St. Petersburg.

\section{Replication and Reconstruction of Sculptures}

For the first time in Russia, the non-contact copying of sculptural monuments was carried out by the scientists of St. Petersburg Electrotechnical University (ETU) in collaboration with Italian colleagues in 2008-2010. It was the project on the replication of the XVIII century Italian marble bust "Primavera" from the State-museum preserve "Tsarskoye Selo" collection. This work began with the creation of a 3D computer model of the sculpture obtained using 3D laser scanning. Then, the 3D model was forwarded to our colleagues in Carrara in Italy, who have years of experience in the creation of replicas of historical objects from natural marble using CNC machines. Firstly, they converted 3D model into CAD model requiring for operation of $\mathrm{CNC}$ robotic machines. After that, they manufactured a precise copy of the sculpture "Primavera" from a block of white Carrara marble by using a CNC milling robotic machine. The detailed description of this project is given in [3,7], and in Figure 1, one can see photos of the original, the process of carving the marble block, and replica placed in the location of the original sculpture. 


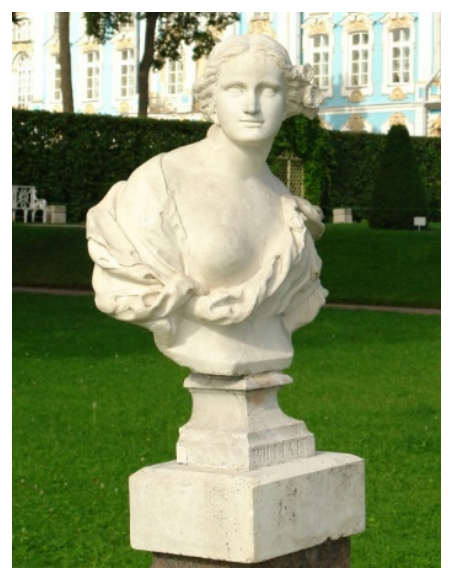

(a)

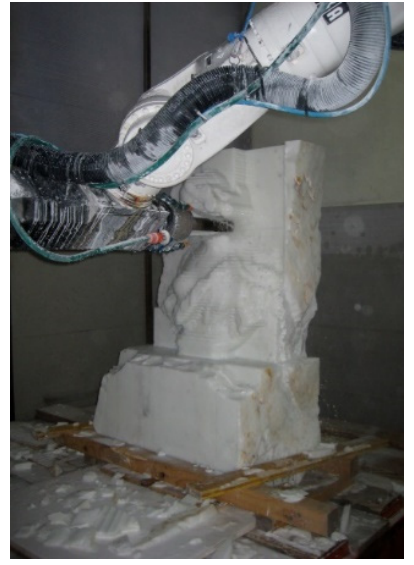

(b)

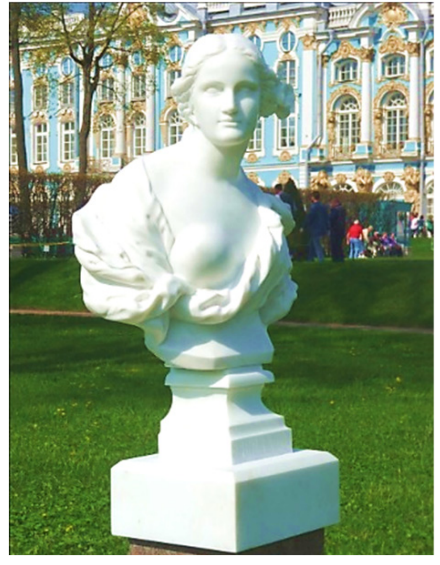

(c)

Figure 1. Marble sculpture "Primavera": general view of original, June 2009 (a); process of manufacturing the replica by CNC machine (b); general view of replica, June 2010 (c).

One more project was conducted by the scientific group of the ETU in 2017 when a copy of marble bust of XIX century of the Russian Emperor Peter the Great from the State-museum preserve "Peterhof" collection marble bust was created. This sculpture was given by Russian sponsoring organizations as a present to the French Academy of Sciences in Paris in 2017 on the occasion of the 300th anniversary of the Peter the Great visit to France. During the implementation of this project, 3D scanning of Peter's bust was carried out in the storage facility of the museum "Peterhof", and then, the same as "Primavera", its copy was made of a marble block in Carrara, Italy by using a CNC machine (Figure 2) [8].

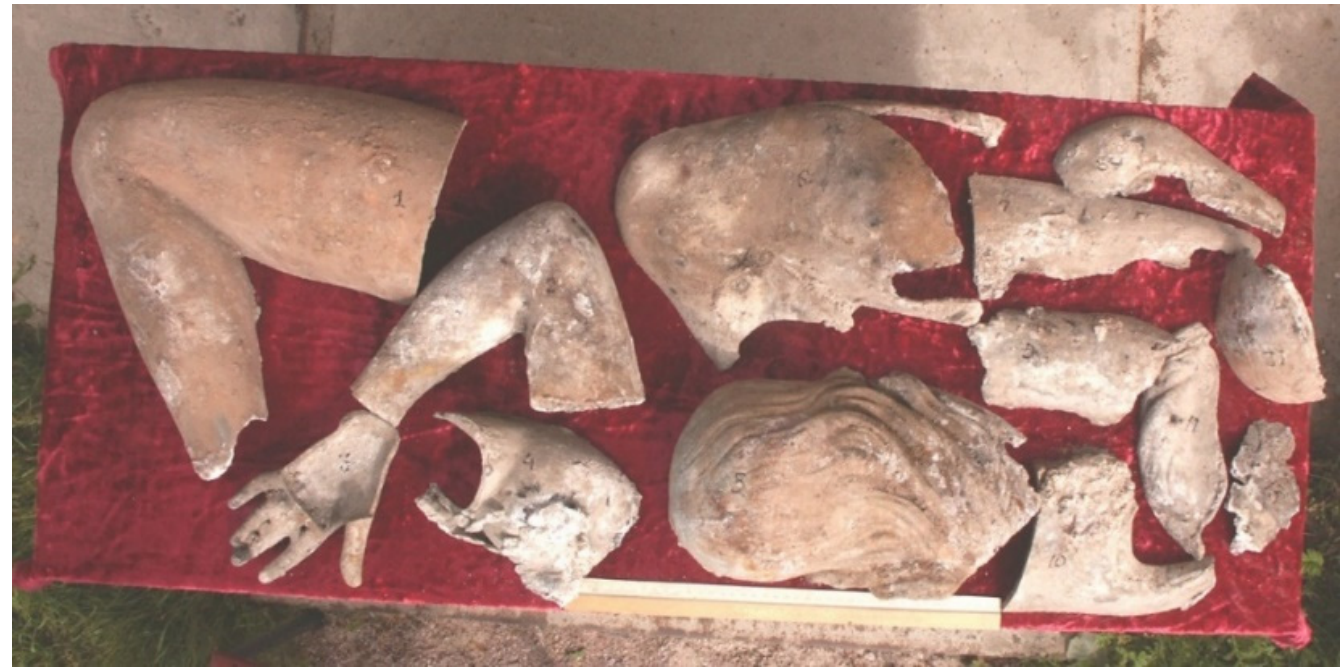

Figure 2. Fragments of sculpture "Eve".

The results of the projects on copying marble sculptures of Peter I and Primavera provide a convincing demonstration of the high efficiency of the contactless method for creating physical copies of sculptural monuments made of stone. Its relatively low cost, speed of execution and the full preservation of the original in the process are of such significance that it will inevitably lead to its wide application in museum practice soon.

\section{Reconstruction of Damaged Cultural Heritage Objects}

Another interesting perspective in modern museum work is connected with the use of 3D scanning for the reconstruction of damaged and even completely destroyed monuments. 


\subsection{Case Study of Zinc Sculpture "Eve"}

One of the case studies of such works is the reconstruction of a totally lost sculpture from the former estate Sergievka in the suburbs of St. Petersburg, which in the XIX century was the country residence of the Duke of Leuchtenberg, the stepson of Napoleon Bonaparte. The Duke of Leichtenberg collected antiquities and possessed the richest collection of masterpieces. Unfortunately, almost all the items of this unique collection were lost during the Great Fatherland War, as Sergievka was in the epicenter of combat activities. Among the many lost masterpieces was a 19th-century zinc sculpture "Eve at the water spring", the fragments of which were discovered underground during construction works in 2007 (Figure 2).

They represented a pile of scattered fragments that did not allow carrying out the reconstruction of this monument by traditional methods of the museum work. However, the use of 3D laser scanning technology, computer simulation, and 3D printing made possible creating a replica of this sculpture, allowing us to judge what the original monument was like (Figure 3). The replica was created from polymer material using additive technology FDM (fused deposition modeling).

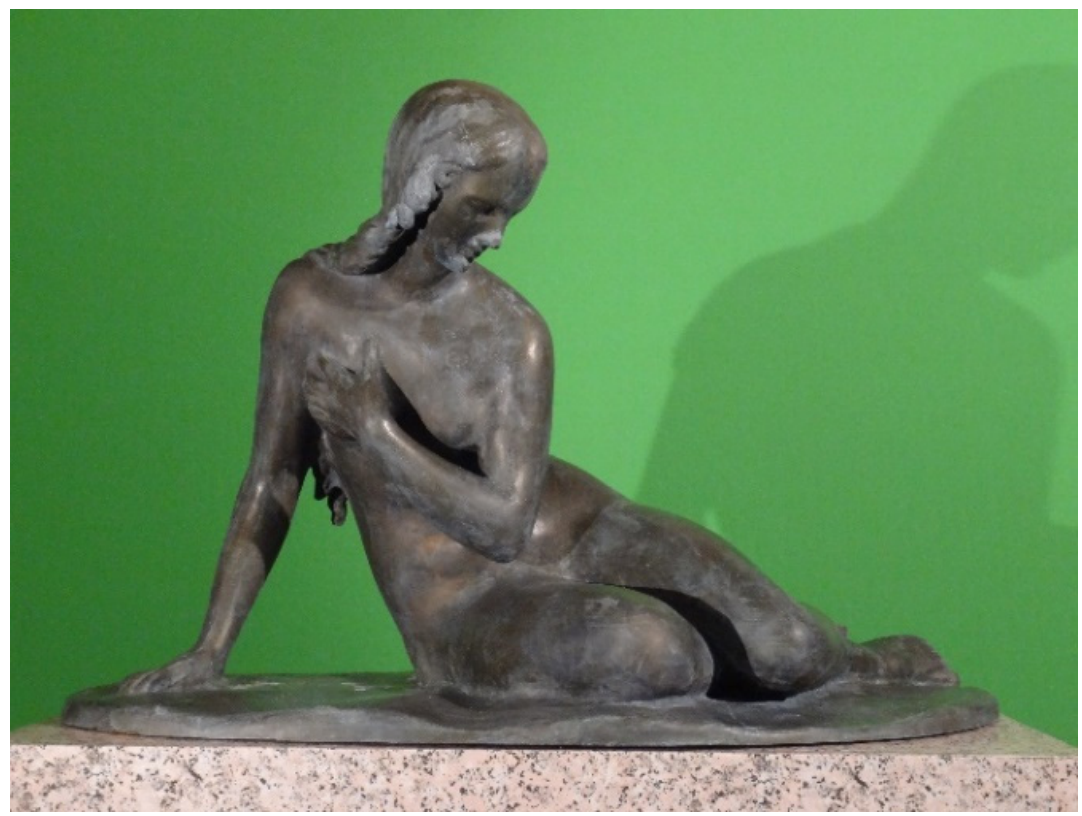

Figure 3. Replica of sculpture "Eve".

The results of this project are described in the work [5], but it is worth mentioning that the replication and reconstruction of works of art puts a serious issue on the agenda-what is the accuracy of creating the physical copies of objects? In other words, how precise is the correspondence between surfaces of the same object in its 3D model and replica obtained using additive technologies? This issue is very important from point of view of authenticity of any original $\mathrm{CH}$ object and its replica, but it is not considered in the scientific literature in the papers devoted to the replication of sculptures.

We carried out an experimental study on the evaluation of the accuracy of the replication of the sculpture "Eve". In those experiments, we used a laser scanner Surphaser 25SHX (scanning accuracy-2.5 microns) and did find that deviations in the surfaces of the original 3D model and replica were in the range of $\pm 0.7 \mathrm{~mm}$. During a detailed analysis of the 3D model of the replica, a "cellular structure" (resembling honeycomb) was clearly visible on its surface, especially pronounced in the area of the sculpture's back (see Figure 4, where one can see the result of "overlapping" of 3D model of replica and 3D model that was used for the creation of replica). 


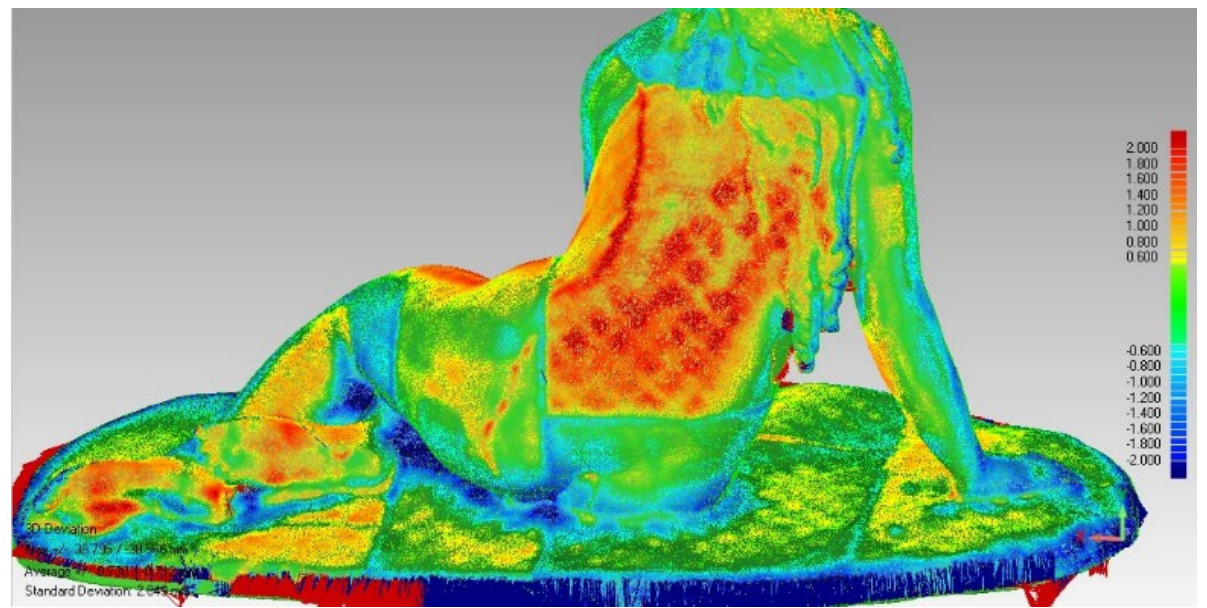

Figure 4. The result of comparing the replica's 3D model and the 3D model that was used to create the replica.

This may be a consequence of the 3D printing technique used, in which, to reduce the cost of replication, we decided to save used material (PLA plastic) by having the sculpture be hollow inside (the volume filling was 10\%). Because of this, local "minima" (deflections) of the sculpture surface are observed in the places where the surface layer of the sculpture is attached to the stiffeners, while the sagging areas correspond to local maxima. It was these deformations that were detected by laser scanning.

Thus, the accuracy of reproduction of the sculpture "Eve" can be considered good, but it must be borne in mind that when replicating sculptural monuments, distortions of their geometric shape are possible.

\subsection{Case Study of Cast-Iron Star}

One of our most recent works relates to the reconstruction of $\mathrm{CH}$ objects created from cast-iron. Nowadays, it is a typical conservation problem in $\mathrm{CH}$ preservation. There are sculptures, objects of decorative art, grids around historical buildings, parks, and gardens as well as just decorative elements on the facades of buildings. Many of them are highly deteriorated and usually have severely damaged and lost parts (see Figure 5a). Until recently, experts in the field of $\mathrm{CH}$ did not attach much importance to such items, and as they fell into complete disrepair, they were replaced with copies. However, in recent years, there has been a reassessment of values, and a new trend has emerged in the work of restorers, which requires the reconstruction of objects damaged by corrosion instead of replacing them with copies.

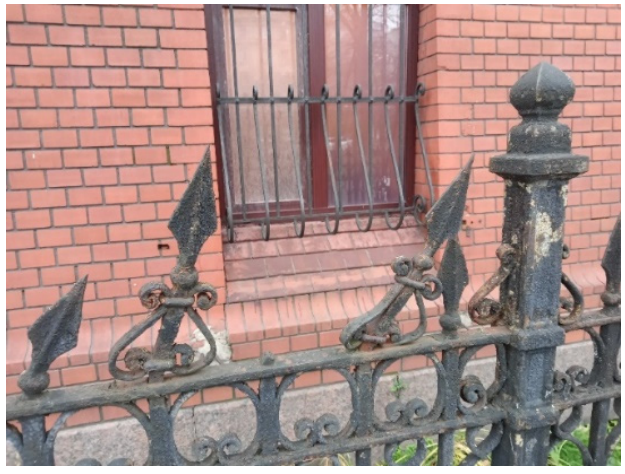

(a)

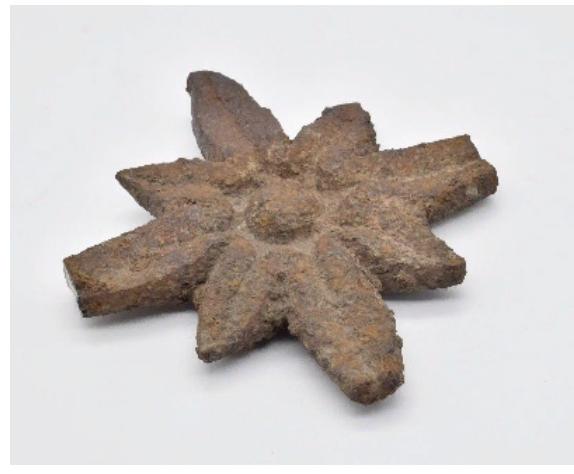

(b)

Figure 5. (a) — An example of a damaged cast-iron fence; (b) — cast-iron star for repairing. 
The authors of this article understand this problem and proposed its technical solution based on the use of laser powder coating technology. In our work, we demonstrated the principal possibility of the realization of such an approach.

The object of our studies was a small $(10 \mathrm{~cm})$ iron star that is a decorative element of a XIX century cast-iron tombstone fence of the Alexander Nevsky monastery in St. Petersburg. This object is highly deteriorated due to corrosion and has losses of some small elements (see Figure 5b).

The main idea of our project was to recreate the losses of individual elements of the star using a combination of 3D scanning technology, direct metal laser sintering (DMLS), and laser cladding.

Firstly, we analyzed the chemical composition of the star using X-ray fluorescence using XL3t-32280 equipment. The analysis results are shown in Table 1.

Table 1. The result of the chemical analysis of the part.

\begin{tabular}{ccccccccccc}
\hline Element & Fe & Si & Co & Mn & P & Zn & Pb & Ti & Ag & Other \\
\hline Content, wt. \% & 91.05 & 6.38 & 0.79 & 0.45 & 0.34 & 0.24 & 0.22 & 0.17 & 0.13 & 0.24 \\
\hline
\end{tabular}

We did find that the main chemical element is Fe (its concentration is of about 91\%). Additionally, there are permanent impurities typical for gray cast-iron (the total concentration is only about $7.2 \%$ ).

Secondly, we removed the corrosion from the star surface. For the removal of corroded layers, we tried to use different treatment techniques: laser cleaning, sand blasting and chemical treatment; the latter gave the best result (see Figure 6a).

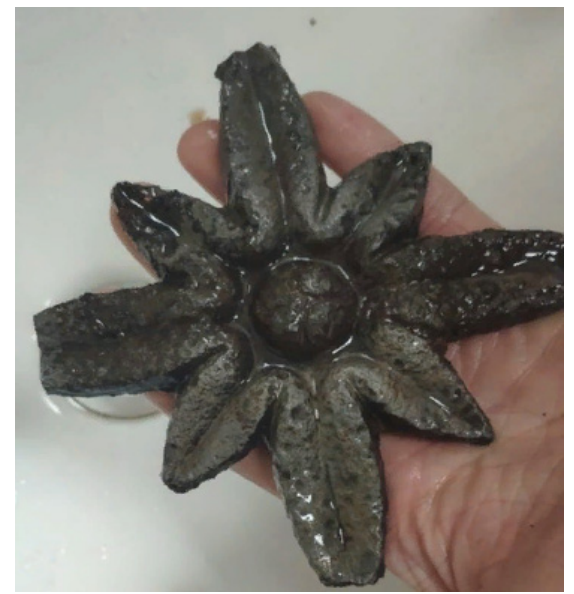

(a)

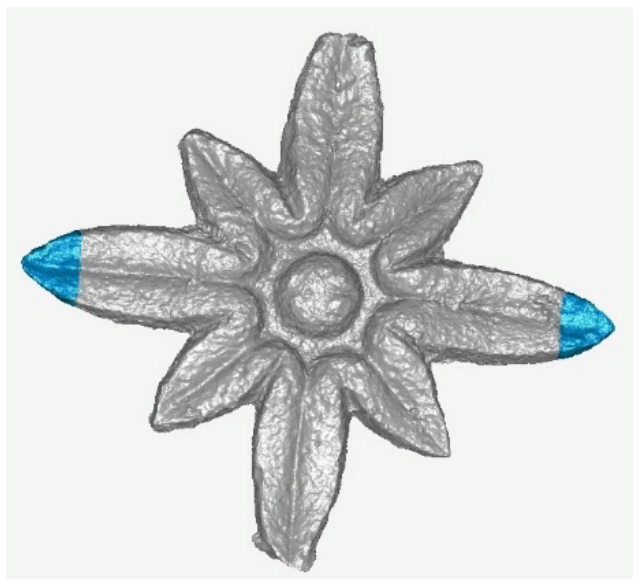

(b)

Figure 6. (a)—star after chemical treatment; (b) —3D model with added rays.

Then, we carried out 3D scanning of the star using laser triangular scanner Konica Minolta V-910 and created its 3D model. The next stage of our work was the computer modeling. The missing ray of the cast-iron star was modeled with the Zbrush software. The main distinguishing feature of this software is the ability to "sculpt" 3D objects. The surviving cones were projected, processed, and "glued" to the main body of the star in the parts where there were losses (see Figure 6b), where blue ends are reconstructed lost parts of the star.

It was decided to separate those experiments into two stages: firstly, we created one of the star rays, which we proposed to join with the star; the second stage of reconstruction will be based on a reconstruction of the lost end of another star ray by direct metal deposition. It is obvious that such a method of reconstruction is more complicated since the very 
precise movement of a laser beam is needed, and such a task can be solved by means of the development of specialized software.

A separate ray of the star was grown by the DMLS method according to the CAD model. We used a CW fiber Ytterbium laser with an output power of up to $80 \mathrm{~W}$. Stainlesssteel powder 316 L20 (manufacturer-Hoganas, Belgium) with a granule size of $53 \mu \mathrm{m}$ was used for printing. The result of creating this piece can be seen in Figure 7a.

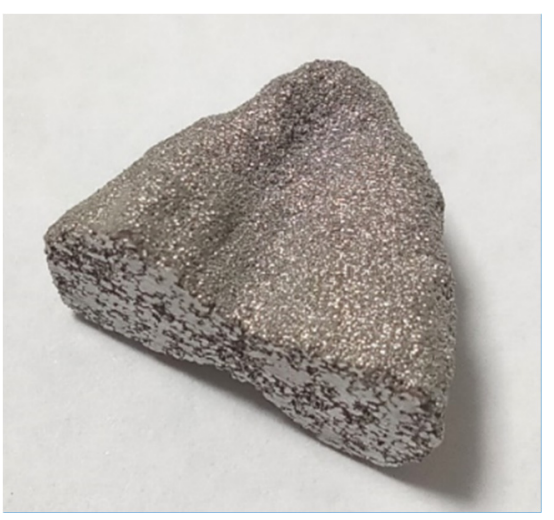

(a)

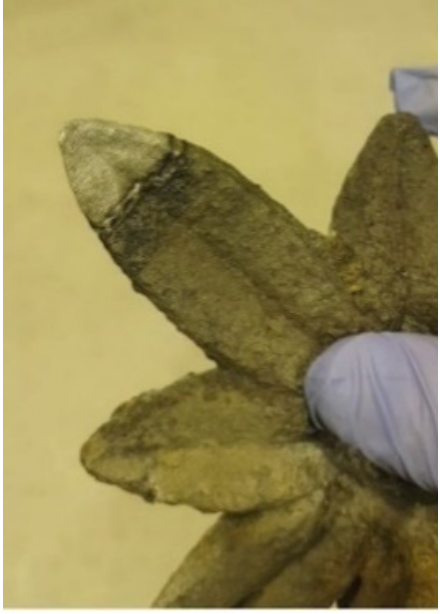

(b)

Figure 7. (a)—DMLS printed star ray; (b) —welded star ray.

We then applied direct laser deposition (DLD) $[9,10]$ using the OKTA-Printer machine developed at the Peter the Great St. Petersburg Polytechnic University (see Figure 8). The essence of the DLD method is to directly feed a metal powder or composite powder mixture into a molten bath formed by a laser beam [11-13]. The local action of heating the laser beam, the selective effect, as well as the high accuracy of modern robotic manipulators allow using this technology as an advanced and modern method for repairing and restoring products. The main parts of the OKTA-Printer are the powder cladding head and the CAMAU robot. For joining, we used a nickel alloy powder Inconel 625 (manufacturer-Hoganas, Belgium) with a particle size distribution of $50-150 \mu \mathrm{m}$. It is one of the most popular alloys in laser cladding and DLD [14,15]. To connect the two pieces, they were glued to each other with glue, then welded in one pass on each side. The following parameters were used for welding: laser spot width $1.5 \mathrm{~mm}$, laser power $700 \mathrm{~W}$, robot movement speed $1500 \mathrm{~mm} / \mathrm{s}$, and powder feed $20 \mathrm{~g} / \mathrm{min}$. The result of the stage of the star reconstruction is shown in Figure $7 \mathrm{~b}$.

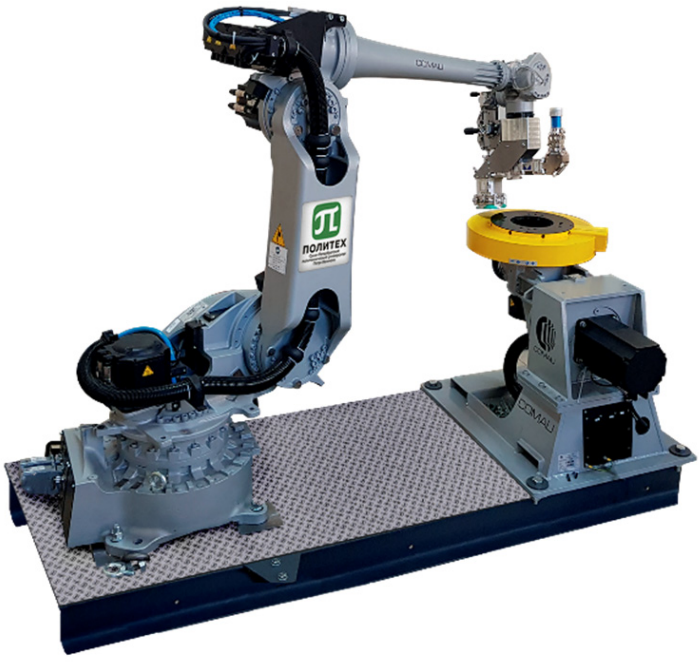

Figure 8. OKTA-Printer implementing DLD technology. 
Using the DLD printer, an attempt was made to deposit the missing part of the star's ray on the material from which it is made. For this, a parallel piece was cut off and deposited on it from the same Inconel 625 that was used for welding. As a result of the cladding, an excessive absorption of laser radiation by the star material was detected, which leads to melting and a geometry change in the substrate along the edges, even with a relatively low heat input.

Furthermore, to assess the thermal effect on the structure of the star material, a materials science study of the initial structure and structure after laser cladding was carried out, and the transition zone was also investigated. Additionally, the microhardness was measured at a load of $0.3 \mathrm{kgf}$ with the same step of $200 \mu \mathrm{m}$ to evaluate the change in metal properties from the nickel alloy overlay to the cast-iron from which the star is made (see Figure 9).

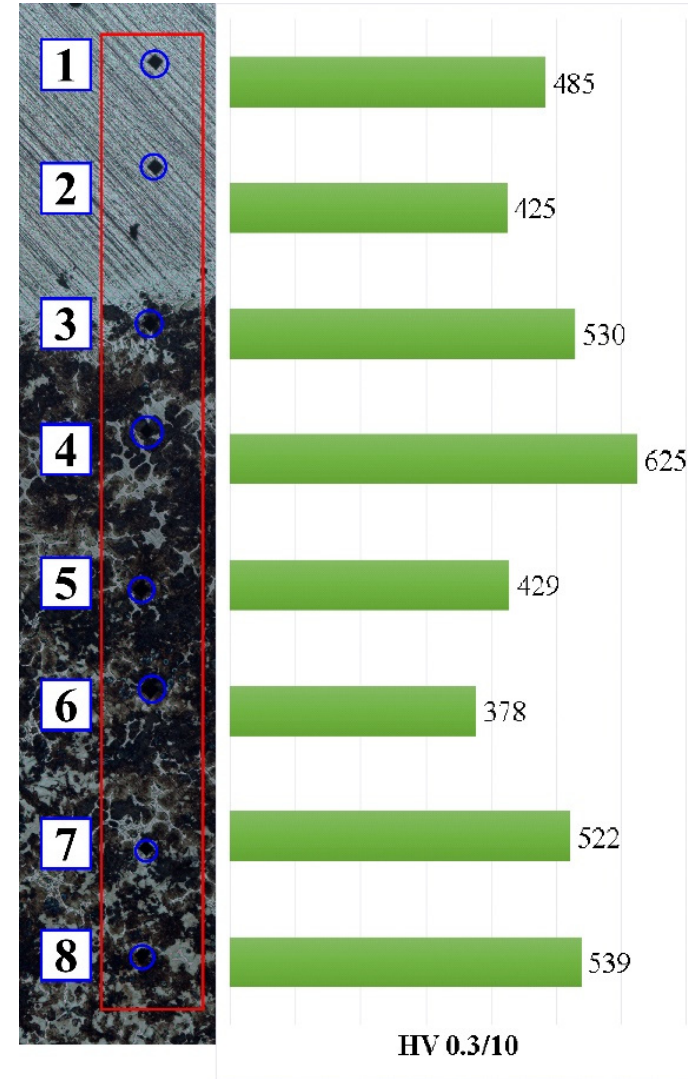

(a)

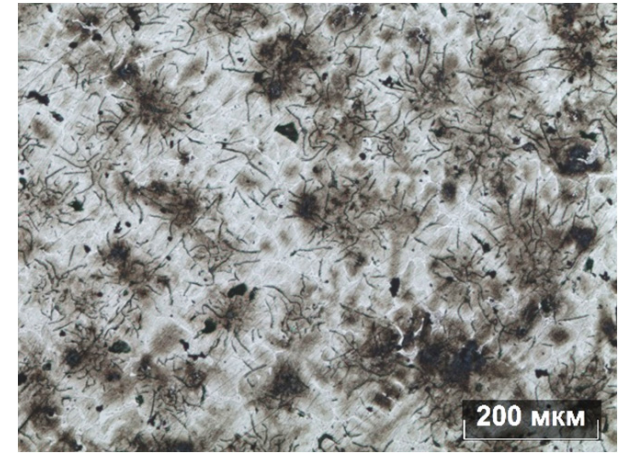

(b)

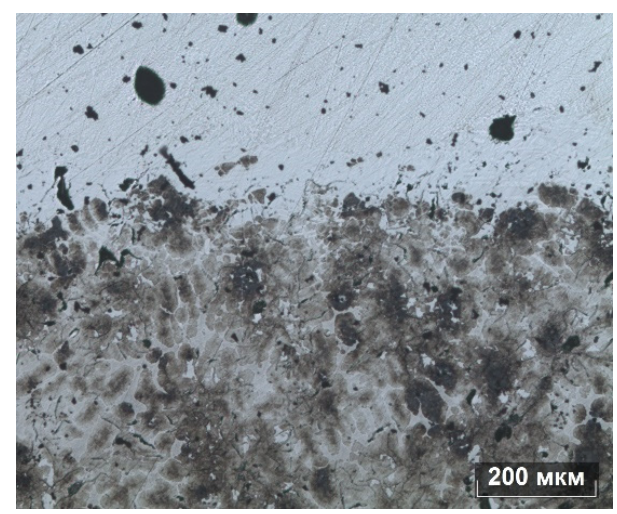

(c)

Figure 9. (a)-hardness measurement in HV from cladding to cast-iron with a step of $200 \mu \mathrm{m}$, the structure of the material was investigated using a Leica optical microscope: (b) - structure of cast-iron-before cladding; (c)—structure of cast-iron with cladding.

Separate hardness measurements were made at four to five points for each area of interest: cast-iron without surfacing is $240 \pm 60 \mathrm{HV}$, with weld overlay $467 \pm 76 \mathrm{HV}$, hardness of deposited Inconel 625 corresponds to $462 \pm 26 \mathrm{HV}$, hardness in the transition zone is $601 \pm 134 \mathrm{HV}$. Examination of the state of the interface on an optical microscope (Figure 9c) showed a strong metallic bond of the cladding with the star material: there were no cracks or pores at the interface.

Since there are no data on the percentage of carbon in the composition of the studied cast-iron, we assume that the initial microstructure of the star material corresponds to the structure of gray cast-iron on a ferrite base with lamellar-free graphite. Due to the thermal effect of the laser beam, the hardness of cast-iron increased significantly, which can be 
associated with rapid heating followed by rapid cooling, which leads to the formation of a pearlite structure, as well as the accumulation of thermal stresses. It was noted that at more than $1 \mathrm{~mm}$ from the surfacing, the hardness of the cast-iron base was significantly higher than the hardness of the same cast-iron without cladding. This indicates a large heat-affected zone that is not typical for standard cladding materials. Usually, this area is no more than $0.5 \mathrm{~mm}$. This is most likely due to the size of the substrate itself and the low heat-dissipation. For the experiment on direct restoration of the missing part, a substrate with an area of $2 \mathrm{~cm}^{2}$ was used, whereas the substrates for cladding and DLD are usually at least $100 \mathrm{~cm}^{2}$.

\section{Conclusions}

This article describes several case studies concerned with the reconstruction and replication of $\mathrm{CH}$ objects in the city of St. Petersburg. It was shown that such tasks can be effectively achieved by means of the combined use of 3D scanning technologies, CNC milling, and laser additive technologies.

It should be noted that, as far as we know, our work on the reconstruction of the cast-iron star was the first case study that demonstrated the principal possibility of the use of direct metal laser sintering and laser powder cladding technology for the conservation of cast-iron $\mathrm{CH}$ objects. Therefore, the combined use of 3D scanning, DMLS, and laser cladding technologies has great potential for exact copying of the texture of metal monuments. The main advantage of this approach is a slight thermal effect on the restoration object at the joining of the reconstructed elements with a damaged object itself by laser cladding. Direct reconstruction of damaged CH objects by the DLD method directly on the object of restoration looks preferable, but it is much more complicated due to the unsuitability of cast iron as a substrate, from which many $\mathrm{CH}$ objects are made. Nevertheless, it is no doubt an interesting field for further scientific work, and the authors plan to continue their studies.

Author Contributions: Conceptualization, V.P.; methodology, V.P.; software, D.M.; validation, V.P. and S.I.; formal analysis, V.P.; investigation, V.P., S.I. and D.K.; resources, V.P. and S.I.; data curation, S.I.; writing—original draft preparation, V.P. and D.K.; writing—review and editing, V.P., S.I.; visualization, V.P., D.K. and S.I.; supervision, V.P.; project administration, V.P., A.O.; funding acquisition, V.P. and D.M. All authors have read and agreed to the published version of the manuscript.

Funding: This research received no external funding.

Institutional Review Board Statement: Not applicable.

Informed Consent Statement: Not applicable.

Data Availability Statement: By request to authors.

Acknowledgments: The authors would like to acknowledge Vitaly Tishkin and Anton Zhuravlev for taking part in the experimental studies.

Conflicts of Interest: The authors declare no conflict of interest. The funders had no role in the design of the study; in the collection, analyses, or interpretation of data; in the writing of the manuscript, or in the decision to publish the results.

\section{References}

1. Fowles, P.S. The Garden Temple at Ince Blundell: A Case Study in the Recording and Non-Contact Replication of Decayed Sculpture. J. Cult. Herit. 2000, 1, S89-S91. [CrossRef]

2. la Pensée, A.; Parsons, J.; Cooper, M.; Broadbent, S.; Bingham, R. The Use of 3D Laser Scanning and 3D Modelling in the Realisation of an Artistic Vision; Production of Large Scale Public Art in Tudor Square, Sheffield. In Proceedings of the International Archives of Photogrammetry, Remote Sensing and Spatial Information Sciences, Newcastle upon Tyne, UK, 21-24 June 2010; Volume XXXVIII, pp. 375-380.

3. Parfenov, V.A. Non-Contact Replication of Marble Sculptures Using Laser Technology. In Sculpture of XVIII-XIX Centuries in Out-Door Environment; St. Petersburg's Museum of Urban Sculpture Publishing House: St. Petersburg, Russia, 2010 ; pp. 66-69.

4. Skarlatos, D.; Theodoridou, S.; Hennings, D.; Ville, S. Replication of Marble Exhibits Using Photogrammetry and Laser Scanning (or How to Forge Exhibits). In Proceedings of the XIXth CIPA Symposium, Antalya, Turkey, 30 September-4 October 2003. 
5. Wachowiak, M.J.; Karas, B.V. 3d Scanning and Replication for Museum and Cultural Heritage Applications. J. Am. Inst. Conserv. 2009, 48, 141-158. [CrossRef]

6. Cekus, D.; Kwiatoń, P.; Nadolski, M.; Sokół, K. Quality Assessment of a Manufactured Bell Using a 3D Scanning Process. Sensors 2020, 20, 7057. [CrossRef] [PubMed]

7. Parfenov, V.A. Laser Techniques in Artworks Conservation in St.Petersburg. Rev. Cuba. Fis. 2016, 33, E29-E31.

8. Parfenov, V.A. Use of Laser Technologies for Restoration, Documentation and Replication of Sculptural Monuments in Saint Petersburg. Insight Non-Destr. Test. Cond. Monit. 2020, 62, 129-133. [CrossRef]

9. Thompson, S.M.; Bian, L.; Shamsaei, N.; Yadollahi, A. An Overview of Direct Laser Deposition for Additive Manufacturing; Part I: Transport Phenomena, Modeling and Diagnostics. Addit. Manuf. 2015, 8, 36-62. [CrossRef]

10. Masaylo, D.V.; Orlov, A.V.; Igoshin, S.D. Effect of Heat Treatment on the Structure and Phase Composition of a High-Temperature Nickel Alloy Obtained by Laser Cladding. Met. Sci. Heat Treat. 2019, 60, 728-733. [CrossRef]

11. Masaylo, D.V.; Popovich, A.A.; Sufiyarov, V.S.; Orlov, A.V.; Shamshurin, A.I. A Study of Structural Features of a Gradient Material from a Heat-Resistant Nickel Alloy Produced by Laser Cladding. Met. Sci. Heat Treat. 2019, 60, 739-744. [CrossRef]

12. Schwendner, K.I.; Banerjee, R.; Collins, P.C.; Brice, C.A.; Fraser, H.L. Direct Laser Deposition of Alloys from Elemental Powder Blends. Scr. Mater. 2001, 45, 1123-1129. [CrossRef]

13. Leyens, C.; Beyer, E. Innovations in Laser Cladding and Direct Laser Metal Deposition. In Laser Surface Engineering; Elsevier: Amsterdam, The Netherlands, 2015; pp. 181-192.

14. Todaro, C.J.; Easton, M.A.; Qiu, D.; Zhang, D.; Bermingham, M.J.; Lui, E.W.; Brandt, M.; StJohn, D.H.; Qian, M. Grain Structure Control during Metal 3D Printing by High-Intensity Ultrasound. Nat. Commun. 2020, 11, 142. [CrossRef] [PubMed]

15. Abioye, T.E.; Folkes, J.; Clare, A.T. A Parametric Study of Inconel 625 Wire Laser Deposition. J. Mater. Process. Technol. 2013, 213, 2145-2151. [CrossRef] 